\title{
Effect of microwave treatment on current flow mechanism in ohmic contacts to GaN
}

\author{
V.N. Sheremet \\ V. Lashkaryov Institute of Semiconductor Physics, NAS of Ukraine, 03028 Kyiv, Ukraine \\ Phone: 38 (044) 525-61-82; fax: 38 (044) 525-61-82; e-mail:VolodymyrSheremet@gmail.com
}

\begin{abstract}
The temperature dependence of contact resistivity $\rho_{c}$ of Ti-Al-TiB 2 -Au ohmic contacts to $n-\mathrm{GaN}$ and effect of microwave treatment on $\rho_{c}$ are investigated. The obtained dependences are described using a model of current flow via metal shunts associated with dislocations, the current being limited by diffusion supply of electrons. It is shown that microwave treatment increases the dislocation density in the near-contact region of contact structure and reduces the relative spread of resistivity values of contacts formed on the wafer.
\end{abstract}

Keywords: ohmic contacts, current flow mechanism, dislocations, contact resistivity, microwave treatment.

Manuscript received 17.05.13; revised version received 26.06.13; accepted for publication 19.09.13; published online 30.09.13.

\section{Introduction}

Development of microelectronics involves production of novel devices as well as modernization of the existing ones. The semiconductor materials used in both processes involve, in particular, such wide-gap semiconductors as $\mathrm{GaN}, \mathrm{SiC}, \mathrm{AlN}$ etc. that enable one to make high-power devices operating at high frequencies. Use of advantages of the above semiconductor materials requires development and application of reliable heat-resistant ohmic contacts. One should also take into account the physical properties of contacts and features of current flow in them.

It is known that such mechanisms of current flow as thermionic and thermofield emissions are characteristic of ohmic contacts. Contact resistivity $\rho_{c}$ decreases exponentially with temperature $T$ at thermionic emission, while remaining independent of $T$ at thermofield emission $[1,2]$. However, in some papers [3-7] non-typical (growing with temperature) dependences $\rho_{c}(T)$ were detected in ohmic contacts. The authors of [3] assumed that these dependences $\rho_{c}(T)$ were related with current flow via metal shunts formed when metal atoms segregate at dislocations, and made qualitative estimation of this process.

In $[5,6]$, a model of current flow via metal shunts, with current limitation by diffusion supply of electrons, was proposed. This model took into account the density of the so-called conducting dislocations (oriented along the normal to the semiconductor surface) and scattering dislocations (oriented at an angle to that normal). It was found that the dislocation density calculated from the dependence $\rho_{c}(T)$ agrees with that obtained experimentally from the etch pit density [8] and X-ray diffraction studies [6]. The model [7] can also describe $\rho_{c}(T)$ curves decreasing with temperature.

In this work, the above model is applied to investigate the temperature dependence of contact resistivity inherent to $\mathrm{Au}_{-} \mathrm{TiB}_{x}-\mathrm{Al}-\mathrm{Ti}-\mathrm{GaN}$ ohmic contacts, both before and after treatment of the samples with microwave irradiation. 


\section{Samples and methods of investigation}

The subjects for investigation were ohmic contacts to heteroepitaxial gallium nitride structures. The latter were VPE-grown from a metal-organic source on an $\mathrm{Al}_{2} \mathrm{O}_{3}$ substrate (with the thickness of $400 \mu \mathrm{m}$ ) at the $\mathrm{CC}$ "Elma-Malachite" (Zelenograd, Russia). The formed structure involved a buffer $n^{+}$-layer with the thickness close to $3 \mu \mathrm{m}$ and donor concentration $N_{d}=10^{18} \mathrm{~cm}^{-3}$ (non-degenerate semiconductor), an $n$-layer (thickness of $1.5 \mu \mathrm{m})$ with $N_{d}=10^{17} \mathrm{~cm}^{-3}$ and a doped cap layer (thickness of $0.8 \mu \mathrm{m}$ ) with $N_{d}=10^{18} \mathrm{~cm}^{-3}$. Doping with $\mathrm{Si}$ was made in the course of growing.

The ohmic contacts were deposited by magnetron sputtering of successive metallization layers $\operatorname{Ti}(50 \mathrm{~nm})$ $\mathrm{Al}(20 \mathrm{~nm})-\operatorname{TiB}_{x}(100 \mathrm{~nm})-\mathrm{Au}(200 \mathrm{~nm})$ in the argon atmosphere onto a gallium nitride surface subjected to photon cleaning (power $P=5 \mathrm{~kW}$, time $t=30 \mathrm{~s}$ ) and heated to $300{ }^{\circ} \mathrm{C}$. After deposition of Ti-Al layers, the samples were subjected to rapid thermal annealing (RTA) in the nitrogen atmosphere at $T=900{ }^{\circ} \mathrm{C}$ for $30 \mathrm{~s}$.

The $\rho_{c}$ value was determined using the transmission line method (TLM) with radial geometry of contact pads $[9,10]$. The contacts were formed using photolithography; the diameters of inner contact pads were $20,40,60,80$ and $100 \mu \mathrm{m}$, and the ratio between the outer and inner radii was 7.4. The structures under investigation were subjected to microwave treatment (radiation frequency of $2.45 \mathrm{GHz}$, emittance of $1.5 \mathrm{~W} / \mathrm{cm}^{2}$, exposure time lied within 1 to $3 \mathrm{~s}$ ). The microwave irradiation of structures was performed in open space at room temperature.

\section{Results and discussion}

The Au-TiB 2 -Al-Ti- $n$-GaN contact structure to be studied was subjected to RTA at $T=900^{\circ} \mathrm{C}$ for $30 \mathrm{~s}$. Their $I-V$ curves were linear and symmetric. It indicated a formed ohmic contact. When measuring $\rho_{c}(T)$ dependences in the 100 to $380 \mathrm{~K}$ temperature range, it was found that the contact resistivity $\rho_{c}$ grew with temperature starting from $T \approx 250 \mathrm{~K}$ (Fig. 1a). It was noted in [3, 4] that such behavior may be caused by conduction via metal shunts (formed by segregation of metal atoms on dislocations) shorting the space-charge region. X-ray diffractometry showed that the dislocation density in the GaN film under investigation was $\geq 10^{8} \mathrm{~cm}^{-2}$ [11], which supported a possibility of such mechanism of current flow.

In [5], a model for current flow via metal shunts, with current limitation by diffusion supply of electrons, was proposed. According to that model, the resistivity of a single shunt in a non-degenerate semiconductor is [7]
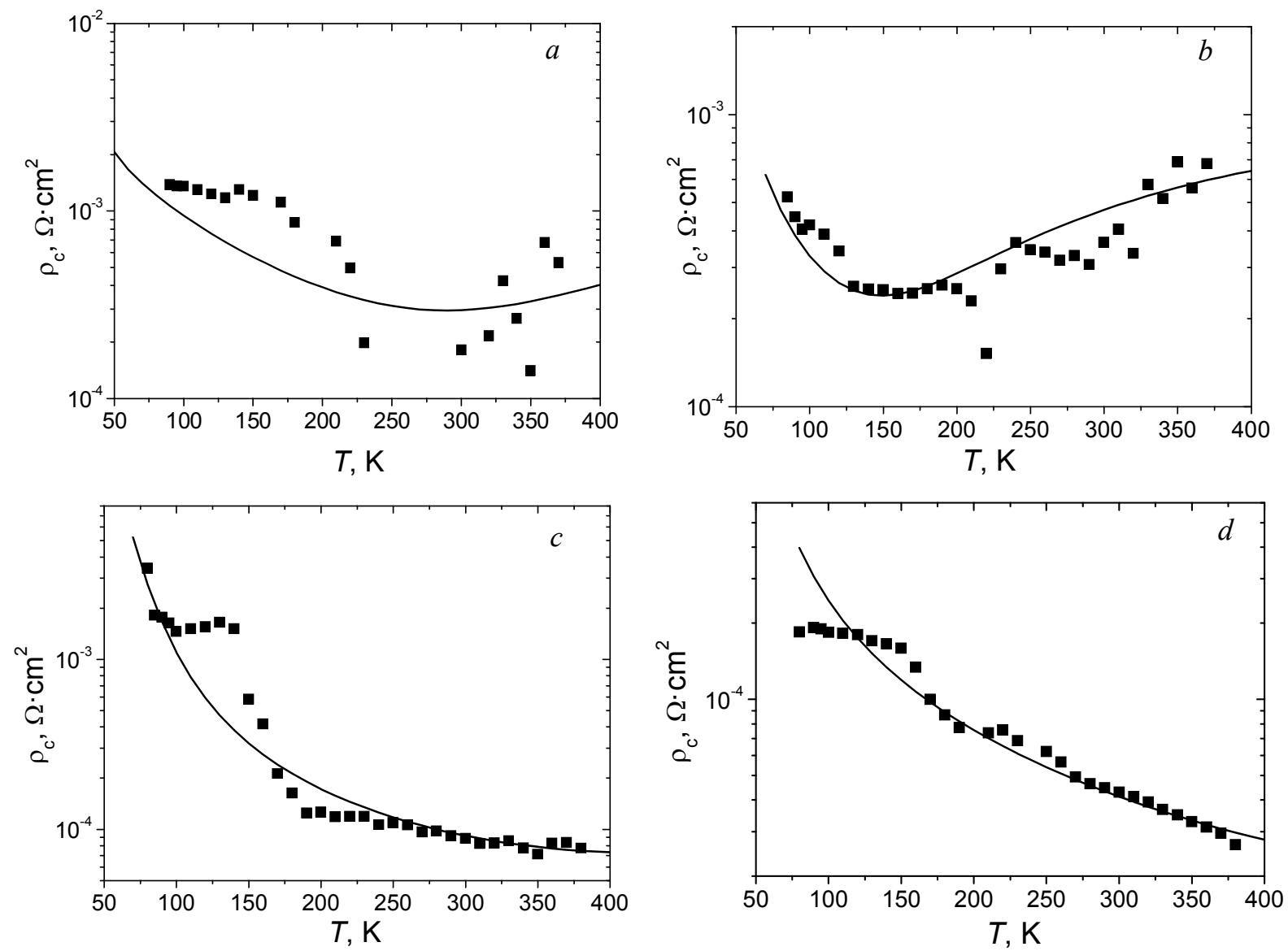

Fig. 1. Temperature dependence of the contact resistivity $\rho_{c}$ before $(a)$ and after microwave treatment for $800(b)$ and $1000 \mathrm{~s}(c)$, and after aging for 270 days $(d)$ at room temperature. 
$\rho_{c 0}=\frac{k T}{q} \frac{\left(1+\frac{V_{T}}{4 D_{n}} e^{y_{c 0}} \alpha L_{\mathrm{D}}\right)}{\frac{q V_{T}}{4} N_{d} e^{y_{c 0}}}$.

Here, $q$ is the elementary charge, $V_{T}$ - mean thermal velocity of electrons, $y_{c 0}=q \varphi_{c 0} / k T$ - nondimensional equilibrium potential at the metalsemiconductor interface, $L_{\mathrm{D}}-$ the Debye shielding length, $D_{n}$ - electron diffusion coefficient, and $\alpha-$ numerical coefficient of the order of unity.

According to Einstein's relation, the electron diffusion coefficient is $D_{n}=k T \mu_{n} / q$, where the electron mobility $\mu_{n}$ is determined with allowance for electron scattering on charged impurities $\left(\mu_{z}\right)$, optical lattice vibrations $\left(\mu_{o}\right)$ and dislocations $\left(\mu_{D}\right)$ :

$\mu_{n}=\left(\mu_{Z}{ }^{-1}+\mu_{\mathrm{o}}^{-1}+\mu_{\mathrm{D}}^{-1}\right)^{-1}$.

The expressions for $\mu_{Z}, \mu_{o}$ and $\mu_{D}$ are as follows [12]:

$$
\mu_{Z}(T)=\frac{3.68 \cdot 10^{20}\left(\frac{\varepsilon_{s}}{16}\right)^{2}\left(\frac{T}{100}\right)^{3 / 2}}{n_{w}\left(\frac{m}{m_{0}}\right)^{1 / 2} \lg \left[1+\left(\left(\frac{\varepsilon_{s}}{16}\right)\left(\frac{T}{100}\right)\left(\frac{2.35 \cdot 10^{19}}{n_{w}}\right)^{1 / 3}\right)^{2}\right]}
$$

and

$$
\mu_{o}(T)=\frac{31.8 \sinh \left(\frac{\theta}{2 T}\right)}{\left(\frac{1}{\varepsilon_{s h}}-\frac{1}{\varepsilon_{s l}}\right) \theta^{0.5}\left(\frac{m}{m_{0}}\right)^{1.5}\left(\frac{\theta}{2 T}\right)^{1 / 2} K_{1}\left(\frac{\theta}{2 T}\right)},
$$

where $n_{w}$ is the ionized impurity concentration, $\theta-$ longitudinal optical phonon temperature, $m$ - electron effective mass, $m_{0}$ - electron mass, $\varepsilon_{s h}\left(\varepsilon_{s l}\right)-$ semiconductor high (low)-frequency permittivity, $K_{1}(\theta / 2 T)$ modified Bessel function of the first order, and

$\mu_{\mathrm{D}}=\frac{B \exp (\eta)}{T^{1 / 2} N_{\mathrm{D} 2} L_{\mathrm{D}}^{5}} K_{2}(\eta)$,

where $N_{D 2}$ is the scattering dislocation density, $\eta=\frac{\hbar^{2}}{16 m L_{\mathrm{D}}^{2} k T}, K_{2}(\eta)-$ modified Bessel function of the second order. A dimensional coefficient $B$ is

$$
B=\frac{\left(\hbar^{2} \varepsilon_{0} \varepsilon_{s l} c\right)^{2}}{8 \sqrt{2 \pi k} q^{3} \sigma^{2} m^{5 / 2}},
$$

where $\sigma=\lambda / 2 q c, \lambda$ is the linear charge density of dislocation line, $c$ - lattice constant along the [0001] direction.

According to $[7,13]$, the temperature dependence of the contact resistivity can be calculated from the following formula: $\rho_{c}=\frac{\rho_{c 0}}{\pi L_{\mathrm{D}}^{2} N_{D 1}}=\frac{k T}{q \pi L_{\mathrm{D}}^{2} N_{D 1}} \frac{\left(1+\frac{V_{T}}{4 D_{n}} e^{y_{c 0}} \alpha L_{\mathrm{D}}\right)}{\frac{q V_{T}}{4} N_{d} e^{y_{c 0}}}$,

where $N_{D 1}$ is the conducting dislocation density.

The dependence $\rho_{c}(T)$ was described using the model for current flow via metal shunts, with current limitation by diffusion supply of electrons. As a result, the density of conducting dislocations $\left(N_{D 1}=\right.$ $\left.5 \cdot 10^{6} \mathrm{~cm}^{-2}\right)$ and scattering dislocations $\left(N_{D 2}=\right.$ $1 \cdot 10^{7} \mathrm{~cm}^{-2}$ ) were obtained (see Fig. 1a). Microwave treatments of the structures under investigations for 800 and $1000 \mathrm{~s}$ led to increase of both conducting and scattering dislocations by an order of magnitude (Table): to $3.3 \cdot 10^{7} \mathrm{~cm}^{-2}$ and $2 \cdot 10^{8} \mathrm{~cm}^{-2}$ after treatment for $800 \mathrm{~s}$ (Fig. 1b) and to $1.3 \cdot 10^{8} \mathrm{~cm}^{-2}$ and $2 \cdot 10^{9} \mathrm{~cm}^{-2}$ after treatment for $1000 \mathrm{~s}$ (Fig. 1c). No considerable changes of dislocation densities were detected after further aging at room temperature for 270 days. They were $N_{D 1}=2.3 \cdot 10^{8} \mathrm{~cm}^{-2}$ and $N_{D 2}=1.8 \cdot 10^{9} \mathrm{~cm}^{-2}$ (see Fig. 1d and Table).

Table. Dislocation density in the Au-TiB $2-A l-T i-n-G a N$ contact structure before (initial sample) and after microwave treatment for 800 and $1000 \mathrm{~s}$ and after aging at room temperature for 270 days.

\begin{tabular}{|l|c|c|c|c|}
\hline \multicolumn{1}{|c|}{ Treatment } & $\begin{array}{c}\rho_{c}(T= \\
300 \mathrm{~K}), \\
\mathrm{Ohm} \cdot \mathrm{cm}^{2}\end{array}$ & $\mid \Delta \rho_{c} / / \rho_{c}$ & $N_{D 1}, \mathrm{~cm}^{-2}$ & $N_{D 2}, \mathrm{~cm}^{-2}$ \\
\hline initial sample & $1.8 \times 10^{-4}$ & 0.61 & $5 \times 10^{6}$ & $1 \times 10^{7}$ \\
\hline $\begin{array}{l}\text { microwave } \\
\text { irradiation } \\
\text { for 800 }\end{array}$ & $3.6 \times 10^{-4}$ & 0.48 & $3.3 \times 10^{7}$ & $2 \times 10^{8}$ \\
\hline $\begin{array}{l}\text { microwave } \\
\text { irradiation } \\
\text { for 1000 s }\end{array}$ & $8.8 \times 10^{-5}$ & 0.45 & $1.3 \times 10^{8}$ & $2 \times 10^{9}$ \\
\hline $\begin{array}{l}\text { aging at } T_{\text {room }} \\
\text { for 270 days }\end{array}$ & $4.1 \times 10^{-5}$ & 0.41 & $2.3 \times 10^{8}$ & $1.8 \times 10^{9}$ \\
\hline
\end{tabular}

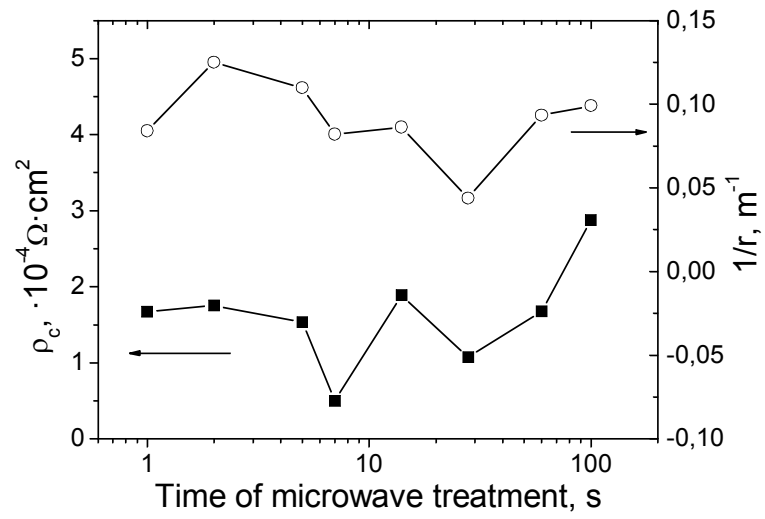

Fig. 2. Dependence of the contact resistivity $\rho_{c}$ and sample curvature on the microwave treatment time. 
The above effect can be explained by using the results of [9], namely, supposition of the role of metal (Ga) inclusions (localized at dislocations) in current flow in the ohmic contact to $n$-GaN. Indeed, it is known that $\mathrm{GaN}$ films may contain excess Ga that forms local inclusions [14]. In the course of microwave treatment (contrary to RTA), local heating of those metal inclusions takes place. Because of low melting temperature of $\mathrm{Ga}\left(29.77^{\circ} \mathrm{C}\right)$, the metal atoms become redistributed over non-uniformities at the metalsemiconductor interface. As a result, the conducting dislocation density increases, thus leading to reduction of the contact resistivity. This is confirmed by reduction of relative spread of $\rho_{c}$ values $\left|\Delta \rho_{c}\right| / \rho_{c}$ of contacts formed on the wafer (Table): it decreases from 0.61 (in the initial structure) down to 0.45 (in the contact structure after microwave treatment for $1000 \mathrm{~s}$ ) and to 0.41 after aging at room temperature for 270 days.

In the course of microwave treatment, relaxation of intrinsic stresses occurs in the metal-semiconductor structure owing to increase in the defect density. This is confirmed by the results of profilometric studies. Shown in Fig. 2 is the dependence of the contact resistivity $\rho_{c}$ and curvature $1 / r$ of a sample with contact metallization (proportional to the stresses in the wafer) on the time of microwave treatment (here $r$ is the radius of curvature). A correlation exists between the above dependences. The estimated correlation coefficient is 0.6. This indicates a considerable effect of intrinsic stresses on the contact resistivity.

The relative spread of contact resistivity values carries information on integral and local properties of the wafer. Therefore, the behavior of relative spread of $\rho_{c}$ values enables one to draw some conclusions concerning the effect of microwave treatment on the local intrinsic stresses. As the time of microwave irradiation grows, the relative spread of contact resistivity values goes down. This may indicate homogenization of local intrinsic stresses because of transformation of the defect structure in the near-contact region of the contact structure under investigation.

\section{Conclusions}

It has been ascertained that in the $\mathrm{Au}-\mathrm{TiB}_{x}-\mathrm{Al}-\mathrm{Ti}-n-\mathrm{GaN}$ contact structure current flows via metal shunts is associated with dislocations and limited by diffusion supply of electrons. The above shunts may be formed by atoms of gallium (whose melting temperature $29.77^{\circ} \mathrm{C}$ is low) segregated at dislocations. Microwave treatment for $1000 \mathrm{~s}$ leads to increase in the dislocation density (owing to relaxation of intrinsic stresses) and redistribution of gallium at the metal-semiconductor interface. This treatment increases the conducting dislocation density, decreases the contact resistivity $\rho_{c}$ of ohmic contacts and reduces the relative spread of contact resistivity values over the wafer. This is confirmed by a correlation between variations of electrical parameters of the contact structure and its curvature.

\section{Acknowledgements}

The author is indebted to research workers of the V. Lashkaryov Institute of Semiconductor Physics of the National Academy of Sciences of Ukraine - Prof. R.V. Konakova, Prof. A.V. Sachenko, Prof. L.A. Matveeva, Dr. V.G. Lyapin for fruitful consultations and interest in this work and researcher E.Yu. Kolyadina for measurement of radii of curvatures of the samples.

\section{References}

1. S.M. Sze, K.K. Ng, Physics of Semiconductor Devices, 3-rd ed. Wiley, 2007.

2. E.H. Rhoderick, R.H. Williams, MetalSemiconductor Contacts, 2-nd ed. Clarendon Press, Oxford, 1988.

3. T.V. Blank, Yu.A. Gol'dberg, O.V. Konstantinov, V.G. Nikitin, E.A. Posse, Peculiarities in the mechanism of current flow through an ohmic contact to gallium phosphide // Techn. Phys. Lett. 30(10), p. 806-809 (2004).

4. T.V. Blank, Yu.A. Gol'dberg, O.V. Konstantinov, V.G. Nikitin, E.A. Posse, The mechanism of current flow in an alloyed In-GaN ohmic contact // Semiconductors, 40(10), p. 1173-1177 (2006).

5. A.E. Belyaev, N.S. Boltovets, R.V. Konakova, Ya.Ya. Kudryk, A.V. Sachenko, V.N. Sheremet, A.O. Vinogradov, Temperature dependence of contact resistance for $\mathrm{Au}-\mathrm{Ti}-\mathrm{Pd}_{2} \mathrm{Si}-n^{+}-\mathrm{Si}$ ohmic contacts subjected to microwave irradiation // Semiconductors, 46(3), p. 330-333 (2012).

6. A.V. Sachenko, A.E. Belyaev, A.V. Bobyl, N.S. Boltovets, V.N. Ivanov, L.M. Kapitanchuk, R.V. Konakova, Ya.Ya. Kudryk, V.V. Milenin, S.V. Novitskii, D.A. Sakseev, I.S. Tarasov, V.N. Sheremet, M.A. Yagovkina, Temperature dependence of the contact resistance of ohmic contacts to III-V compounds with a high dislocation density // Semiconductors, 46(3), p. 334-341 (2012).

7. A.V. Sachenko, A.E. Belyaev, N.S. Boltovets, R.V. Konakova, Ya.Ya. Kudryk, S.V. Novitskii, V.N. Sheremet, J. Li, S.A. Vitusevich, Mechanism of contact resistance formation in ohmic contacts with high dislocation density // J. Appl. Phys. 111(8), 083701 (2012).

8. A.V. Sachenko, A.E. Belyaev, N.S. Boltovets, A.O. Vinogradov, L.M. Kapitanchuk, R.V. Konakova, V.P. Kostylyov, Ya.Ya. Kudryk, V.P. Kladko, V.N. Sheremet, The mechanism of contact-resistance formation on lapped $n$-Si surfaces // Semiconductors, 47(3), p. 449-454 (2013). 
9. A.E. Belyaev, N.S. Boltovets, S.A. Vitusevich, V.N. Ivanov, R.V. Konakova, Ya.Ya. Kudryk, A.A. Lebedev, V.V. Milenin, Yu.N. Sveshnikov, V.N. Sheremet, Effect of microwave treatment on current flow mechanisms in $\mathrm{Au}-\mathrm{TiB}_{x}-\mathrm{Al}-\mathrm{Ti}-n^{+}-n-$ $n^{+}-\mathrm{GaN}-\mathrm{Al}_{2} \mathrm{O}_{3}$ ohmic contacts // Semiconductors, 44(6), p. 745-751 (2010).

10. V.N. Sheremet, Metrological aspects of measuring resistance of ohmic contacts // Radioelectronics and Communications Systems, 53(3), p. 119-128 (2010).

11. A.E. Belyaev, N.S. Boltovets, V.N. Ivanov, V.P. Klad'ko, R.V. Konakova, Ya.Ya. Kudrik, A.V. Kuchuk, V.V. Milenin, Yu.N. Sveshnikov, V.N. Sheremet, Mechanism of dislocation- governed charge transport in Schottky diodes based on gallium nitride // Semiconductors, 42(6), p. 689693 (2008).

12. K. Seeger, Semiconductor Physics. SpringerVerlag, Wien, 1973.

13. A.V. Sachenko, A.E. Belyaev, N.S. Boltovets, A.O. Vinogradov, V.P. Kladko, R.V. Konakova, Ya.Ya. Kudryk, A.V. Kuchuk, V.N. Sheremet, S.A. Vitusevich, Features of temperature dependence of contact resistivity in ohmic contacts on lapped $n$-Si // J. Appl. Phys. 112(6), 063703 (2012).

14. Yu.G. Shreter, Yu.T. Rebane, V.A. Zykov, V.G. Sidorov, Wide-gap Semiconductors. Nauka, St.-Petersburg, 2001 (in Russian). 